\title{
Meta-analysis of the Effects of Alcohol in Diabetes
}

\section{Short and medium-term effects of moderate ethanol intake on glycaemic control in diabetes mellitus - a systematic review and meta-analysis}

\author{
Jennifer A Hirst ${ }^{1}$, Jeffrey K Aronson ${ }^{1}$, Benjamin G Feakins ${ }^{1}$, Chang Ma $^{2}$, Andrew J Farmer ${ }^{1}$, \\ Richard J Stevens ${ }^{1}$
}

\author{
${ }^{1}$ Nuffield Department of Primary Care Health Sciences, University of Oxford, Radcliffe Observatory \\ Quarter, Woodstock Road, Oxford, OX2 6GG, United Kingdom, and National Institute for Health \\ Research School for Primary Care Research \\ ${ }^{2}$ Department of Biomedical Sciences, University of Oxford, Oxford, UK
}

Corresponding author:

Jennifer Hirst

Nuffield Department of Primary Care Health Sciences

University of Oxford

Radcliffe Observatory Quarter

Woodstock Road

Oxford, OX2 6GG

United Kingdom

Tel: +44 (0)1865 617945

e-mail: jennifer.hirst@phc.ox.ac.uk

Word count: 2018

Funding: None

Conflicts of interest: None

Novelty of study:

- Guidelines suggest that drinking alcohol can result in hypoglycaemia in people with diabetes mellitus.

- Studies to date provide no evidence that drinking moderate amounts of alcohol in the short or medium term affects glycaemic control in people with diabetes mellitus 


\begin{abstract}
People with diabetes are told that drinking alcohol may increase their risk of hypoglycaemia. This systematic review reports the effects of alcohol consumption on glycaemic control in people with diabetes mellitus. Medline, Embase, and the Cochrane library databases were searched in 2015 to identify randomised controlled trials comparing alcohol consumption and no alcohol use, reporting glycaemic control in subjects with diabetes. Data on blood glucose, HbA1c and numbers of hypoglycaemic episodes were pooled using random effects metaanalysis. Pooled data from nine short-term studies showed no difference in blood glucose concentrations between those who drank alcohol in doses of 16-80 g (median $20 \mathrm{~g}$ or 2.5 units) compared with those who did not drink alcohol at times of 0.5, 2, 4, and 24 hours after alcohol consumption. Pooled data from four medium-term studies showed that there was no difference in blood glucose or $\mathrm{HbA}_{1 \mathrm{c}}$ concentrations at the end of the study between those who drank 11-18 g alcohol/day (median $12 \mathrm{~g} /$ day or 1.5 units/day) for 4-52 weeks and those who did not. We found no evidence of a difference in hypoglycaemic episodes or withdrawal rates between the randomised groups. Studies to date have not provided evidence that drinking moderate amounts of alcohol, with or without a meal, affects any measure of glycaemic control in people with diabetes mellitus. These results suggest that there is no need to advise people with diabetes to abstain from drinking moderate quantities of alcohol.
\end{abstract}




\section{Introduction}

Hypoglycaemia is of major concern to patients with diabetes mellitus [1], and there is a perception that alcohol consumption may increase the risk of hypoglycaemia. Patientoriented websites from organisations such as the American Diabetes Association [2] and Diabetes UK [3] give mixed messages, advising that "most people with diabetes can have a moderate amount of alcohol" or "there is no need to give up alcohol", and on the same page that "alcohol can cause hypoglycaemia" or "drinking alcohol makes hypoglycaemia ... more likely", without citing supporting evidence $[2,3]$.

In considering the interpretation of "moderate" alcohol consumption in such statements, we note that the definition varies from country to country. In the UK, according to guidelines of the House of Commons Science and Technology Committee in 2011 [4] "men should not regularly drink more than three to four units a day and women no more than two to three units a day", where "regularly" means every day or on most days of the week; this is described as "sensible drinking" and "moderate consumption" and elsewhere "lower risk drinking" [5]. The US Dietary Guidelines for Americans [6] define moderate alcohol consumption as "average daily consumption of up to one drink per day for women and up to two drinks per day for men, with no more than three drinks in any single day for women and no more than four drinks in any single day for men."

During a patient consultation on a previous project [7], whether alcohol affects glycaemic control was the question raised by more patients than any other drug interaction. We have therefore carried out a systematic review of randomised controlled trials of short-term and medium-term effects of alcohol on glycaemic control in people with diabetes.

\section{Patients and methods}

We registered our protocol in advance on the Prospero database [8]. We sought eligible studies in Medline, EMBASE and the Cochrane database of registered controlled trials from 1946 to 5 May 2015. Additionally we scanned reference lists of reviews and relevant papers and searched Clinical trials.gov clinical trials registry. The Medline search strategy is shown in the on-line appendix, A1. Two reviewers independently screened all identified studies for eligibility and extracted the data. We included studies of any duration in which people with diabetes were randomised to alcohol or a control group and reported glycaemic control as an outcome. Glycaemic control, the primary outcome, was assessed from $\mathrm{HbA}_{1 \mathrm{c}}$, blood glucose, and hypoglycaemic episodes. Secondary outcomes were lipid concentrations and adverse events. We also extracted data on study characteristics (alcohol type and dose, length of follow-up) and patient characteristics (age, sex, BMI, and diabetes duration). The dose of alcohol, where not reported, was estimated from the reported volume drunk using a nomogram [9]. We assessed the quality of included studies by recording randomisation method, blinding, intention-to-treat analysis, and attrition rates [10]. We wrote to the authors of studies to request unpublished data.

We separately analysed studies that involved short-term and medium-term alcohol use. The longest short-term study lasted 2 days and the shortest medium-term study lasted 4 weeks. 
For short-term studies we combined data on blood glucose concentrations at 0.5, 2, 4, and 24 hours (or overnight) after alcohol consumption across the studies. For medium-term studies we pooled data on mean $\mathrm{HbA}_{1 \mathrm{c}}$, blood glucose and lipid concentrations at the end of the study. We pooled the $\mathrm{HbA}_{1 \mathrm{c}}$ data only in studies that lasted 8 weeks or longer [11].

\section{Statistical methods}

Analyses were carried out using Stata 12.1SE (StataCorp, Tx). Blood glucose and lipid concentrations reported as $\mathrm{mg} / \mathrm{dl}$ were converted to $\mathrm{mmol} / \mathrm{L}$. End-point blood glucose, $\mathrm{HbA}_{1 \mathrm{c}}$, and blood lipids were pooled using a random-effects DerSimonian and Laird metaanalysis reporting mean difference. One short-term study which only reported change in blood glucose was also included [12]. Numbers of hypoglycaemic events were pooled using the Peto method to calculate odds ratio, because of cells with no events. Patient withdrawal rates were pooled using the Mantel Haenszel method to calculate risk ratio. We imputed standard deviations in studies in which they were not reported by averaging standard deviations from all the studies where they were reported for that comparison, as recommended in the Cochrane Handbook [10], and we approximated the geometric mean to the mean. In sensitivity analyses we excluded studies in which these approximations were made, and a single study in which it was unclear whether all the groups were randomised [13].

\section{Results}

The flow chart for searches is shown in Figure 1. We identified 1308 studies in our initial search, and a further four studies by scanning reference lists. We removed duplicates, leaving 1044 articles to review for eligibility based on titles and abstracts. We then reviewed 42 papers for full eligibility, and excluded 30, for the reasons shown in Figure 1. This left 12 studies for meta-analysis: eight were short-term studies [12, 14-20], three were medium-term studies [13, 21, 22], and one reported both short- and medium-term outcomes [23].

Characteristics of the included studies are shown in Table 1. Mean patient age was 54 years and mean duration of diabetes 9 years. In the medium-term studies the subjects were randomised to wine compared to no wine or "non-alcoholic" beer. In short-term studies patients were randomised to wine ( 3 studies), ethanol (6 studies) or vodka ( 2 comparisons). Comparator groups in the short-term studies were fruit juice, non-alcoholic beer, alcohol-free wine, water, or nothing. Two studies included a meal taken with the drink in both intervention and comparator groups $[15,16]$. Three medium-term studies reported $\mathrm{HbA}_{1 \mathrm{c}}$ as an outcome, and three reported blood glucose. None of the included studies specified the method of randomisation used or whether patients or researchers were blinded to the randomised groups.

\section{Short-term studies}

All short-term studies were a cross-over design. The doses of alcohol were $16-80 \mathrm{~g}$, median $20 \mathrm{~g}$ (2.5 units). Blood glucose concentration 30 minutes after alcohol, reported in 5 studies (8 comparisons) (Figure 2), was not significantly different in those who were randomised to alcohol and those in the comparator groups (mean difference $0.25 \mathrm{mmol} / \mathrm{L}, 95 \% \mathrm{CI}-0.43$ to 
0.94). The results at 2,4 , and 24 hours after alcohol were similar (mean difference -0.12 , $95 \% \mathrm{CI}-0.80$ to 0.57 after 2 hours; $-0.09,95 \% \mathrm{CI}-0.50$ to 0.32 after 4 hours; and $0.19,95 \%$ CI -0.56 to 0.94 after 24 hours; Figure 2).

Stratifying by insulin use and sensitivity analyses gave similar results (not shown). Of the six studies in which hypoglycaemia or other adverse events were reported, five reported no events in either study arm and one reported a total of three hypoglycaemic events, one in the control group and two in the alcohol group [20] (Appendix A2).

\section{Medium-term studies}

Three studies (including 257 participants) were included in the meta-analysis of end-point blood glucose (Figure 3a). The doses of alcohol were 11-18 g/day (median $12 \mathrm{~g} /$ day or 1.5 units/day) for 4-52 weeks. There was a non-significant mean difference in blood glucose concentration between those randomised to alcohol and those in the comparator groups: $-0.39 \mathrm{mmol} / \mathrm{L}(95 \% \mathrm{CI}-1.08$ to 0.29$)$.

The mean difference in $\mathrm{HbA}_{1 \mathrm{c}}$ in three studies (4 comparisons, including 292 participants) between those randomised to alcohol and those in comparator groups was $0.08 \%$ (95\% CI -0.13 to 0.29 ) (Figure $3 b$ ).

Three studies reported numbers of hypoglycaemic episodes; one of the studies with two comparisons did not record any episodes of hypoglycaemia over the course of the study.[13] There was no significant difference between the alcohol and comparator groups (odds ratio = $0.63,95 \%$ CI 0.19 to 2.15; Appendix A2). Similarly, there was no difference in withdrawal rates between the groups (risk ratio $=0.94,95 \%$ CI 0.21 to 4.13; Appendix A3). There was no significant difference in lipid concentrations between the alcohol and comparator groups (mean difference HDL: $0.30 \mathrm{mmol} / \mathrm{L}, 95 \% \mathrm{CI}-0.28$ to 0.89 , LDL: $-0.11 \mathrm{mmol} / \mathrm{L}, 95 \% \mathrm{CI}$ -0.37 to 0.15 , TG: $-0.12 \mathrm{mmol} / \mathrm{L}, 95 \% \mathrm{CI}-0.27$ to 0.03 ). Sensitivity analyses gave similar results (blood glucose mean difference $=-0.62 \mathrm{mmol} / \mathrm{L}, 95 \% \mathrm{CI}-1.74$ to $0.49, \mathrm{HbA}_{1 \mathrm{c}}$ mean difference $=0.08 \%,-0.19$ to 0.35 )

\section{Discussion}

Summary of findings

This is the first systematic review and meta-analysis of randomised studies of the effect of alcohol on glycaemic control in people with diabetes mellitus. We have examined the effects of single doses of alcohol on blood glucose concentrations and the effects of medium-term moderate alcohol use on blood glucose and $\mathrm{HbA}_{1 \mathrm{c}}$. Drinking moderate quantities of alcohol with or without a meal had no significant effect on any measure of glycaemic control in people with diabetes mellitus. We did not find an effect of alcohol on acute hypoglycaemic events, which were rare in both alcohol and control arms.

There is randomised trial evidence that drinking moderate amounts of alcohol in people with diabetes improves metabolic markers, with improvements in HDL cholesterol, triglycerides, and apoB101/apoA1 ratio[24] and a reduced cardiovascular risk[25] which is consistent with meta-analysis data in people without diabetes [26]. We have not been able to confirm this in 
our review. There is a U-shaped relationship between alcohol use and the development of diabetes. ${ }^{28}$ Light to moderate alcohol consumption may protect against type 2 diabetes [2729]. Conversely, high alcohol consumption is reported to be a risk factor for diabetes [30, 31]. The mechanisms for this dual effect may be protection by improved insulin sensitivity at low to moderate doses [32] and pancreatic damage at high doses [33]; there may also be a contribution from obesity caused by long-term alcohol [34]. This work consolidates and extends previous literature $[35,36]$, providing the best available evidence that there is no effect of short-term or medium-term moderate alcohol consumption on glycaemic control.

\section{Limitations}

Most of the included studies did not specify whether and how long before entry the participants had abstained from alcohol. Thus, we cannot tell whether alcohol has different effects in drinkers and non-drinkers. However, that did not appear to be the case in 224 wellcontrolled alcohol abstaining patients with diabetes, and moderate alcohol consumption has beneficial effects on glycaemic control in these patients and on other markers of cardiometabolic risk [24]. We have not been able to assess very long-term use of alcohol in diabetes, as the longest study lasted only two years.

\section{Clinical implications}

Advice from patient-oriented websites that people with diabetes do not need to refrain from drinking alcohol in moderation is supported by the available evidence [2,3]. Cautions from the same organisations that alcohol causes hypoglycaemia are not supported by the evidence base, which is strongest for low to moderate alcohol consumption. However, higher alcohol consumption and other risky behaviours may never be addressed by randomised studies in diabetes, and therefore caution about the potential dangers of excessive alcohol is likely to be the safest course.

\section{Acknowledgements}

Thank you to anonymous members of a patient and public involvement group, by whose concerns this project was motivated. AF receives support from the NIHR Oxford Biomedical Research Centre and is an NIHR Senior Investigator.

\section{Author contributions}

$\mathrm{JH}$ designed the study, performed literature searches, data extraction, oversaw the statistical analyses, and drafted the manuscript, BF contributed to screening of articles data extraction and interpretation of results, CM contributed to screening of articles, data extraction and statistical analysis, AF contributed to study design, interpretation of results, and discussion, JKA contributed to study design, interpretation of results, and discussion, RS contributed to study design, interpretation of results, and discussion and provided statistical support. All authors reviewed and edited the manuscript and approved the final version. 


\section{References}

1. Cryer PE, Davis SN, Shamoon H. Hypoglycemia in diabetes. Diabetes Care. 2003;26(6):1902-12.

2. ADA. Alcohol 2014 [20 August 2015]. Available from: http://www.diabetes.org/food-andfitness/food/what-can-i-eat/making-healthy-food-choices/alcohol.html.

3. Diabetes_UK. Alcohol 2015 [20 July 2015]. Available from: https://www.diabetes.org.uk/Guide-to-diabetes/Managing-your-diabetes/Alcohol/.

4. House_of_Commons_Science_and_Technology_Committee. Alcohol guidelines - Eleventh Report of Session 2010-122011 25 Aug 2015. Available from: http://www.publications.parliament.uk/pa/cm201012/cmselect/cmsctech/1536/1536.pdf.

5. NHS_Choices. Alcohol misuse [25 Aug 2015]. Available from: http://www.nhs.uk/conditions/alcohol-misuse/Pages/Introduction.aspx.

6. Department_of_Health. Scientific report of the 2015 dietary guidelines advisory committee2015 27 Aug 2015. Available from: http://health.gov/dietaryguidelines/2015-scientificreport/pdfs/scientific-report-of-the-2015-dietary-guidelines-advisory-committee.pdf.

7. Hirst JA, Farmer AJ, Feakins BG, Aronson JK, Stevens RJ. Quantifying the effects of diuretics and beta-adrenoceptor blockers on glycaemic control in diabetes mellitus - a systematic review and meta-analysis. British journal of clinical pharmacology. 2015;79(5):733-43.

8. Hirst J, Stevens R, Feakins B, Aronson J, Farmer A. Protocol for systematic review and metaanalysis of the effects of alcohol on glycaemic control in diabetes PROSPERO International prospective register of systematic reviews [Internet]. 2014; CRD42014008806. Available from: http://www.crd.york.ac.uk/PROSPERO/display record.asp?ID=CRD42014008806.

9. Mellor CS. Nomogram for calculating mass of alcohol in different beverages. British medical journal. 1970;3(5724):703.

10. Cochrane Collaboration. Cochrane handbook for systematic reviews of interventions. 2011. Available from: http://handbook.cochrane.org/.

11. Hirst JA, Stevens RJ, Farmer AJ. Changes in HbA1c Level over a 12-Week Follow-up in Patients with Type 2 Diabetes following a Medication Change. PLoS One. 2014;9(3):e92458.

12. Gin H, Rigalleau V, Caubet O, Masquelier J, Aubertin J. Effects of red wine, tannic acid, or ethanol on glucose tolerance in non-insulin-dependent diabetic patients and on starch digestibility in vitro. Metabolism: Clinical and Experimental. 1999;48 (9):1179-83.

13. Nakamura T, Fujiwara N, Sugaya T, Ueda Y, Koide H. Effect of red wine on urinary protein, 8-hydroxydeoxyguanosine, and liver-type fatty acid-binding protein excretion in patients with diabetic nephropathy. Metabolism: Clinical and Experimental. 2009;58 (8):1185-90.

14. Christiansen C, Thomsen C, Rasmussen O, Glerup H, Berthelsen J, Hansen C, et al. Acute effects of graded alcohol intake on glucose, insulin and free fatty acid levels in non-insulin-dependent diabetic subjects. European Journal of Clinical Nutrition. 1993;47(9):648-52.

15. Christiansen C, Thomsen C, Rasmussen O, Hauerslev C, Balle M, Hansen C, et al. Effect of alcohol on glucose, insulin, free fatty acid and triacylglycerol responses to a light meal in non-insulindependent diabetic subjects. Br J Nutr. 1994;71(3):449-54.

16. Dalgaard M, Thomsen C, Rasmussen BM, Holst JJ, Hermansen K. Ethanol with a mixed meal decreases the incretin levels early postprandially and increases postprandial lipemia in type 2 diabetic patients. Metabolism: Clinical and Experimental. 2004;53 (1):77-83.

17. Foot EA, Eastmond R. Good metabolic and safety profile of troglitazone alone and following alcohol in NIDDM subjects. Diabetes Research and Clinical Practice. 1997;38 (1):41-51.

18. Kerr D, Penfold S, Zouwail S, Thomas P, Begley J. The influence of liberal alcohol consumption on glucose metabolism in patients with type 1 diabetes: a pilot study. Qjm. 2009;102(3):169-74.

19. Koivisto VA, Tulokas S, Toivonen M, Haapa E, Pelkonen R. Alcohol with a meal has no adverse effects on postprandial glucose homeostasis in diabetic patients. Diabetes Care. 1993;16(12):1612-4.

20. Walsh CH, O'Sullivan DJ. Effect of moderate alcohol intake on control of diabetes. Diabetes. 1974;23(5):440-2. 
21. Marfella R, Cacciapuoti F, Siniscalchi M, Sasso FC, Marchese F, Cinone F, et al. Effect of moderate red wine intake on cardiac prognosis after recent acute myocardial infarction of subjects with Type 2 diabetes mellitus. Diabetic Medicine. 2006;23 (9):974-81.

22. Shai I, Wainstein J, Harman-Boehm I, Raz I, Fraser D, Rudich A, et al. Glycemic effects of moderate alcohol intake among patients with type 2 diabetes: a multicenter, randomized, clinical intervention trial. Diabetes Care. 2007;30(12):3011-6.

23. Bantle AE, Thomas W, Bantle JP. Metabolic effects of alcohol in the form of wine in persons with type 2 diabetes mellitus. Metabolism: Clinical and Experimental. 2008;57 (2):241-5.

24. Shai I, Gepner Y, Golan R, Harman-Boehm L, Henkin Y, Schwarzfuchs D, et al. What is the effect of wine intake in type 2 diabetes and does the wine color matter? A 2-year randomized controlled trial. Obestity facts. 2015;8(suppl 1):32.

25. Solomon CG, Hu FB, Stampfer MJ, Colditz GA, Speizer FE, Rimm EB, et al. Moderate alcohol consumption and risk of coronary heart disease among women with type 2 diabetes mellitus. Circulation. 2000;102(5):494-9.

26. Rimm EB, Williams P, Fosher K, Criqui M, Stampfer MJ. Moderate alcohol intake and lower risk of coronary heart disease: meta-analysis of effects on lipids and haemostatic factors. BMJ. 1999;319(7224):1523-8.

27. Beulens JW, van der Schouw YT, Bergmann MM, Rohrmann S, Schulze MB, Buijsse B, et al. Alcohol consumption and risk of type 2 diabetes in European men and women: influence of beverage type and body size The EPIC-InterAct study. J Intern Med. 2012;272(4):358-70.

28. Koppes LL, Dekker JM, Hendriks HF, Bouter LM, Heine RJ. Moderate alcohol consumption lowers the risk of type 2 diabetes: a meta-analysis of prospective observational studies. Diabetes Care. 2005;28(3):719-25.

29. Metcalf PA, Scragg RK, Jackson R. Light to moderate alcohol consumption is protective for type 2 diabetes mellitus in normal weight and overweight individuals but not the obese. J Obes. 2014;2014:634587.

30. Carlsson S, Hammar N, Efendic S, Persson PG, Ostenson CG, Grill V. Alcohol consumption, Type 2 diabetes mellitus and impaired glucose tolerance in middle-aged Swedish men. Diabet Med. 2000;17(11):776-81.

31. Cullmann M, Hilding A, Ostenson CG. Alcohol consumption and risk of pre-diabetes and type 2 diabetes development in a Swedish population. Diabet Med. 2012;29(4):441-52.

32. Kiechl S, Willeit J, Poewe W, Egger G, Oberhollenzer F, Muggeo M, et al. Insulin sensitivity and regular alcohol consumption: large, prospective, cross sectional population study (Bruneck study). BMJ. 1996;313(7064):1040-4.

33. Lee SS, Hong OK, Ju A, Kim MJ, Kim BJ, Kim SR, et al. Chronic Alcohol Consumption Results in Greater Damage to the Pancreas Than to the Liver in the Rats. Korean J Physiol Pharmacol. 2015;19(4):309-18.

34. Breslow RA, Chen CM, Graubard BI, Jacobovits T, Kant AK. Diets of drinkers on drinking and nondrinking days: NHANES 2003-2008. The American journal of clinical nutrition. 2013;97(5):1068-75.

35. Howard AA, Arnsten JH, Gourevitch MN. Effect of alcohol consumption on diabetes mellitus: a systematic review. Ann Intern Med. 2004;140(3):211-9.

36. Pietraszek A, Gregersen S, Hermansen K. Alcohol and type 2 diabetes. A review. Nutr Metab Cardiovasc Dis. 2010;20(5):366-75. 
Table 1 - List of included studies

\begin{tabular}{|c|c|c|c|c|c|c|c|c|c|c|c|}
\hline \multicolumn{12}{|c|}{ Short-term studies } \\
\hline Authors (ref) & Year & $\begin{array}{c}\text { Total } \\
\text { number }\end{array}$ & Intervention & $\mathbf{n}$ & $\begin{array}{l}\text { Mean } \\
\text { alcohol } \\
\text { dose } \\
\text { (approx) }\end{array}$ & Comparator & $\mathbf{n}$ & $\begin{array}{l}\text { Times of BG } \\
\text { measurement } \\
\text { (hours) }\end{array}$ & $\begin{array}{l}\text { Mean } \\
\text { age }\end{array}$ & $\begin{array}{l}\text { Insulin } \\
\text { use }\end{array}$ & $\begin{array}{l}\text { Length of } \\
\text { study }\end{array}$ \\
\hline Bantle [23] & 2008 & 18 & White wine & 18 & $24 \mathrm{~g}$ & $\begin{array}{l}\text { White grape } \\
\text { juice }\end{array}$ & 18 & $2,4,24$ & 64 & No & overnight \\
\hline $\begin{array}{l}\text { Christiansen } \\
{[14]}\end{array}$ & 1993 & 10 & $\begin{array}{l}\text { Ethanol + non- } \\
\text { alcoholic beer }\end{array}$ & 10 & $24 \mathrm{~g}$ & $\begin{array}{l}\text { Non-alcoholic } \\
\text { beer }\end{array}$ & 0 & $0.5,2,4$ & 66 & No & $4 h$ \\
\hline $\begin{array}{l}\text { Christiansen } \\
{[15]}\end{array}$ & 1994 & 10 & $\begin{array}{l}\text { Ethanol + non- } \\
\text { alcoholic beer } \\
+ \text { food }\end{array}$ & 10 & $24 \mathrm{~g}$ & $\begin{array}{l}\text { Non-alcoholic } \\
\text { beer }+ \text { food }\end{array}$ & 10 & $0.5,2,4$ & 55 & No & $4 \mathrm{~h}$ \\
\hline Dalgaard [16] & 2004 & 11 & $\begin{array}{l}\text { 40g ethanol } \\
+ \text { food }\end{array}$ & 11 & $40 \mathrm{~g}$ & Food & 11 & $0.5,2,4,24$ & 63 & No & $8 \mathrm{~h}$ \\
\hline $\begin{array}{l}\text { Foot - placebo } \\
{[17]}\end{array}$ & 1997 & 12 & $\begin{array}{l}\text { Ethanol in } \\
\text { orange juice }\end{array}$ & 12 & $45 \mathrm{~g}^{*}$ & $\begin{array}{l}\text { Orange juice } \\
\text { alone }\end{array}$ & 12 & $0.5,2,4,24$ & 56 & No & $24 \mathrm{~h}$ \\
\hline $\begin{array}{l}\text { Foot - } \\
\text { troglitazone } \\
{[17]}\end{array}$ & 1997 & 11 & $\begin{array}{l}\text { Ethanol in } \\
\text { orange juice }\end{array}$ & 11 & $45 \mathrm{~g}^{*}$ & $\begin{array}{l}\text { Orange juice } \\
\text { alone }\end{array}$ & 11 & $0.5,2,4,24$ & 64 & No & $24 \mathrm{~h}$ \\
\hline Gin [12] & 1999 & 10 & $\begin{array}{l}\text { Red wine }+ \\
\text { meal }\end{array}$ & 10 & $16 \mathrm{~g} *$ & Water & 10 & $0.5,2,4$ & 53 & No & $5 \mathrm{~h}$ \\
\hline Gin [12] & 1999 & 10 & $\begin{array}{l}\text { Ethanol + } \\
\text { meal }\end{array}$ & 10 & $16 \mathrm{~g}$ & No ethanol & 10 & $0.5,2,4$ & 53 & No & $5 \mathrm{~h}$ \\
\hline Kerr [18] & 2009 & 12 & White wine & 12 & $48-80 \mathrm{~g}$ & $\begin{array}{l}\text { Alcohol-free } \\
\text { wine }\end{array}$ & 12 & 2,4 & 44 & Yes & $4 \mathrm{~h}$ \\
\hline Kovisto [19] & 1993 & 10 & $\begin{array}{l}\text { Vodka, red } \\
\text { wine \& cognac }\end{array}$ & 10 & $61 \mathrm{~g} *$ & Mineral water & 10 & 0.5 & 34 & Yes & overnight \\
\hline Kovisto [19] & 1993 & 16 & $\begin{array}{l}\text { Vodka, red } \\
\text { wine \& cognac }\end{array}$ & 16 & $61 \mathrm{~g} *$ & Mineral water & 16 & $0.5,2,4,24$ & 34 & No & overnight \\
\hline Walsh [20] & 1974 & 20 & $\begin{array}{l}\text { Ethanol + diet } \\
\text { orange + and } \\
\text { water }\end{array}$ & 20 & $28 \mathrm{~g}$ & No drink & 20 & 24 & 63 & $7 / 20$ & $24 \mathrm{~h}$ \\
\hline
\end{tabular}




\begin{tabular}{|c|c|c|c|c|c|c|c|c|c|c|c|}
\hline \multicolumn{12}{|c|}{ Medium-term studies } \\
\hline Authors (ref) & Year & $\begin{array}{c}\text { Total } \\
\text { number }\end{array}$ & Intervention & $\mathbf{n}$ & $\begin{array}{l}\text { Mean } \\
\text { daily } \\
\text { alcohol } \\
\text { dose } \\
\end{array}$ & Comparator & $\mathbf{n}$ & Outcome & $\begin{array}{l}\text { Mean } \\
\text { age }\end{array}$ & $\begin{array}{l}\text { Insulin } \\
\text { use }\end{array}$ & $\begin{array}{l}\text { Length of } \\
\text { trial } \\
\text { (weeks) }\end{array}$ \\
\hline Bantle [23] & 2008 & 17 & Wine & 17 & $18 \mathrm{~g}$ & No wine & 17 & $\begin{array}{l}\text { Blood } \\
\text { glucose }\end{array}$ & 64 & No & 4 \\
\hline Marfella [21] & 2006 & 131 & $\begin{array}{l}\text { A 4-oz glass of } \\
\text { red wine each } \\
\text { day }\end{array}$ & 57 & $11 \mathrm{~g}$ & $\begin{array}{l}\text { No red wine or } \\
\text { other alcohol } \\
\text { consumption }\end{array}$ & 58 & $\begin{array}{l}\text { Blood } \\
\text { glucose \& } \\
\mathrm{HbA}_{1 \mathrm{c}}\end{array}$ & 36 & ns & 52 \\
\hline Nakamura [13] & 2009 & 36 & Red wine & 12 & $12 \mathrm{~g}$ & No wine & 12 & $\mathrm{HbA}_{1 \mathrm{c}}$ & 55 & $36 \%$ & 26 \\
\hline Nakamura [13] & 2009 & 36 & White wine & 12 & $12 \mathrm{~g}$ & No wine & 12 & $\mathrm{HbA}_{1 \mathrm{c}}$ & 55 & $36 \%$ & 26 \\
\hline Shai [22] & 2007 & 109 & $\begin{array}{l}3 / 4 \text { Red wine, } 1 / 4 \\
\text { white wine }\end{array}$ & 75 & $13 \mathrm{~g}$ & $\begin{array}{l}\text { Non-alcoholic } \\
\text { diet malt beer }\end{array}$ & 34 & $\begin{array}{l}\text { Blood } \\
\text { glucose \& } \\
\mathrm{HbA}_{1 \mathrm{c}}\end{array}$ & 61 & some & 12 \\
\hline
\end{tabular}


Figure 1 - Flow chart of searches

Figure 2- Mean difference in blood glucose $(\mathrm{mmol} / \mathrm{mol})$ at $0.5,2,4$ and 24 hours after randomisation to alcohol or comparator calculated by the DerSimonian and Laird random effects model in short-term studies. Horizontal bars and diamond widths represent $95 \%$ CIs and box sizes indicate relative weights in the analysi.s Asterisks indicate studies in populations using insulin.

Figure 3 - Mean difference in (a) endpoint blood glucose (mmol/L) and (b) endpoint $\mathrm{HbA}_{1 \mathrm{c}}(\%)$ with alcohol versus placebo (boxes) and pooled estimates (diamond) calculated by the DerSimonian and Laird random effects model in medium-term studies. Horizontal bars and diamond widths represent 95\% CIs and box sizes indicate relative weights in the analysis

\section{Figure 1 - flow chart}
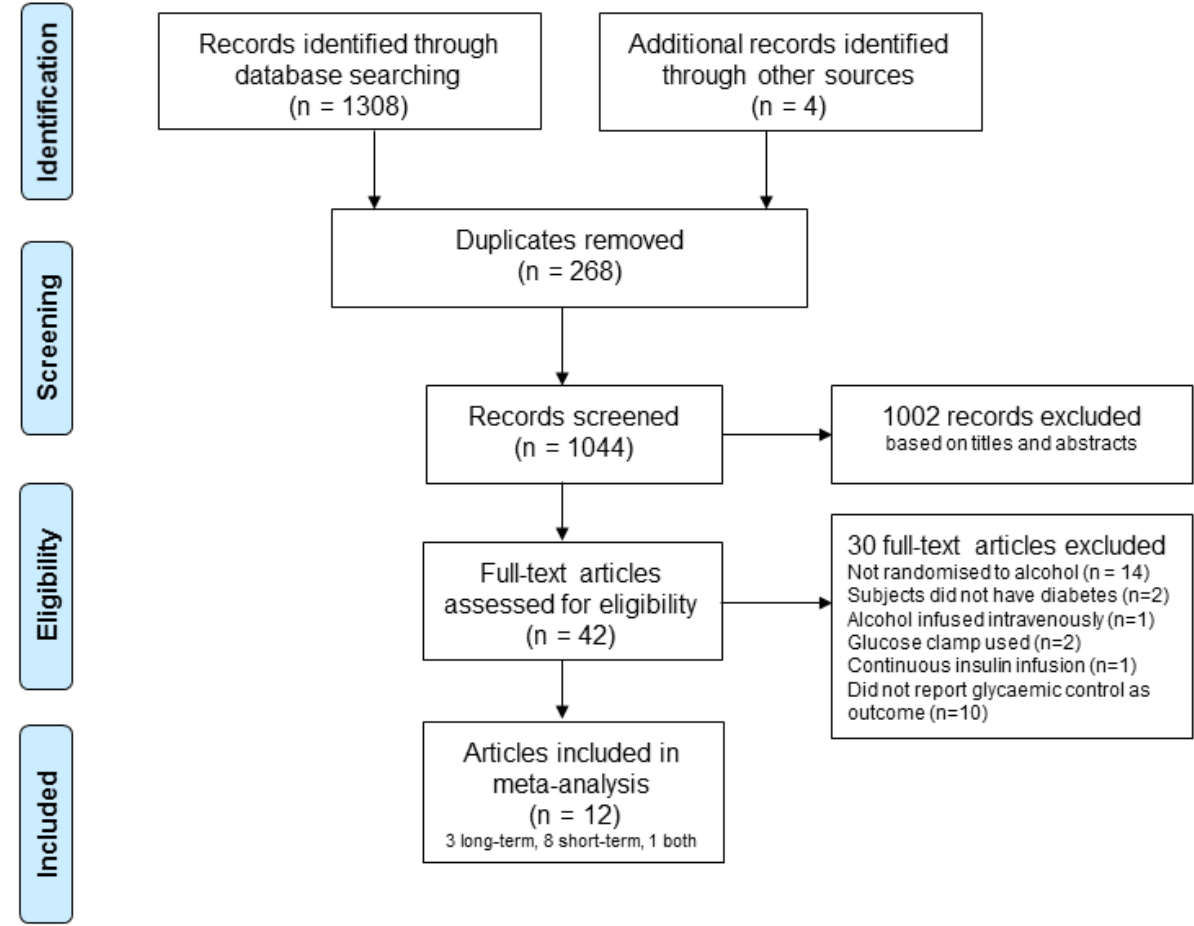

Articles included in meta-analysis

3 long-term, 8 short-term, 1 both 


\section{Figure 2}

Study

30 minutes

Christiansen (1994)

Christiansen (1993)

Kovisto type I (1993)*

Gin - wine (1999)

Gin - ethanol (1999)

Foot troglitazone (1997)

Foot placebo (1997)

Kovisto type II (1993)

Subtotal ( -squared $=0.0 \%, p=0.997$ )

2 hours

Gin - ethanol (1999)

Christiansen (1993)

Gin - wine (1999)

Kerr (2009) $)^{*}$

Kovisto type I (1993) $)^{\star}$

Christiansen (1994)

Foot troglitazone (1997)

Dalgaard (2004)

Foot placebo (1997)

Kovisto type II (1993)

Bantle (2008)

Subtotal $(I-$ squared $=0.0 \%, p=0.989$ )

4 hours

Kovisto type I (1993)*

Kerr (2009)*

Christiansen (1993)

Christiansen (1994)

Gin - wine (1999)

Gin - ethanol (1999)

Foot troglitazone (1997)

Dalgaard (2004)

Foot placebo (1997)

Kovisto type II (1993)

Bantle (2008)

Subtotal $($-squared $=0.0 \%, p=0.979$ )

24 hours / Overnight

Kovisto type I (1993)*

Foot troglitazone (1997)

Foot placebo (1997)

Kovisto type II (1993)

Bantle (2008)

Walsh $(1974)^{\star}$

Subtotal (l-squared $=0.0 \%, p=0.950)$
Glucose

$(\mathrm{mmol} / \mathrm{l})(95 \% \mathrm{Cl})$

$0.73(-1.83,3.29)$

$-0.17(-5.71,5.37)$

$-0.48(-2.89,1.93)$

$0.20(-2.71,3.11)$

$0.20(-0.78,1.18)$

$0.85(-1.80,3.50)$

$0.00(-2.53,2.53)$

$0.55(-1.30,2.40)$

$0.25(-0.43,0.94)$

$-0.20(-1.73,1.33)$

$-0.05(-5.79,5.69)$

$0.49(-3.23,4.21)$

$-0.20(-3.36,2.96)$

$0.00(-2.41,2.41)$

$1.07(-1.75,3.89)$

$0.36(-2.44,3.16)$

$-0.76(-2.17,0.65)$

$-0.91(-3.59,1.77)$

$0.00(-2.19,2.19)$

$0.70(-1.45,2.85)$

$-0.12(-0.80,0.57)$

$0.39(-2.09,2.87)$

$-1.60(-4.20,1.00)$

$0.17(-2.60,2.94)$

$0.79(-1.78,3.36)$

$-1.36(-4.68,1.96)$

$0.10(-0.61,0.81)$

$-0.09(-2.10,1.92)$

$-0.09(-1.03,0.85)$

$-0.60(-2.53,1.33)$

$0.00(-1.97,1.97)$

$-0.20(-1.05,0.65)$

$-0.09(-0.50,0.32)$

$1.74(-2.65,6.13)$

$0.20(-3.03,3.43)$

$1.23(-1.86,4.32)$

$0.47(-2.03,2.97)$

$0.00(-0.89,0.89)$

$0.28(-3.16,3.72)$

$0.19(-0.56,0.94)$ 
Figure 3

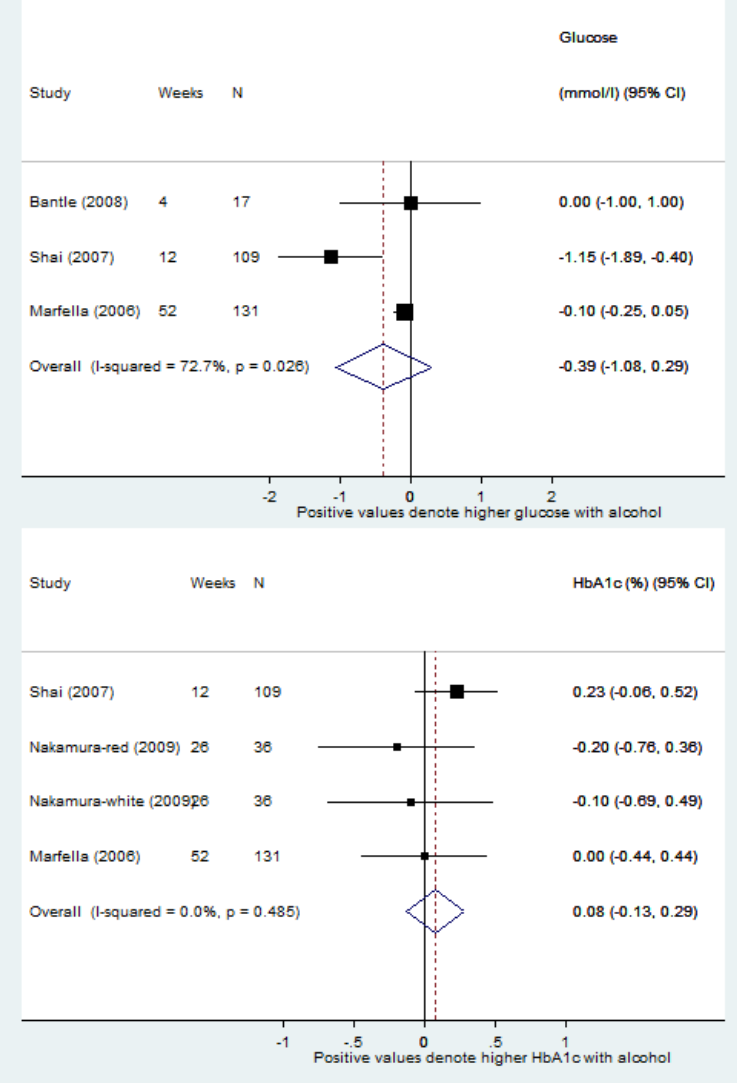

